\title{
An Overview of the Practice of Traffic Impact Assessment in Malaysia
}

\author{
Lim Wei May, Raha Abd Rahman, Mohod Farid Hassin, Jezan Md Diah, Nordiana Mashros, \\ Mohd Ezree Abdullah, Mohd Idrus Bin Mohd Masirin
}

\begin{abstract}
Malaysia is a developing country with rapid urbanisation, unceasing development and growing expansion of road network, connecting all the major cities in the country. However, in the downfall, traffic congestions, road accidents and fatalities are still at an alarming level, so to control the traffic impacts generated, the government uses Traffic Impact Assessment (TIA) as planning tool to assess the feasibility and rationality of a development. In Malaysia, TIA has been applied since early 90', with the first draft TIA guidelines proposed in 2005 and was revised in 2011 by Road Engineering Association of Malaysia (REAM) to the guidelines for TIA used today. TIA is about assessing the adverse impacts generated by a proposed development and mitigating the impacts with the appropriate measurements. Since TIA is adopted, developing countries are still facing various issues which happens also in Malaysia. This study will discuss about those issues and provide a method to assess the performance of TIA in Malaysia by determining what constitute to the best practice from an international standard and where Malaysia stand in the standard. The findings from the study will provide the necessary information for the future amendments in the practice of TIA.
\end{abstract}

Catchphrases: Case Study; Guidelines; Framework; Traffic Impact Assessment.

\section{INTRODUCTION}

The world is at a rapid pace of urbanisation, cities expanding, changing the countries social structure and travel patterns [1]. Urban cities were experiencing serious traffic problems as the demand is surpassing the transportation system's capacity because more households could afford private vehicles. In this environment with increasing usage in private vehicles caused heavy traffic flows, traffic congestion, frustrations on road and environmental degradation [2]. If not mitigated at the early stage of land use planning, the growing of traffic will soon suffocate the already congested condition consequently leading to more

Revised Manuscript Received on April 19, 2019.

Lim Wei May, Department of Civil and Environmental Engineering, Universiti Tun Hussein Onn Malaysia, Parit Raja, Batu Pahat, Johor, Malaysia.

Raha Abd Rahman, Department of Civil and Environmental Engineering, Universiti Tun Hussein Onn Malaysia, Parit Raja, Batu Pahat, Johor, Malaysia.

Mohd Farid Hassin, Pejabat Tanah Kluang, Kluang, Johor, Malaysia

Jezan Md Diah, Malaysia Institute of Transport, Universiti Tecknologi MARA, Shah Alam, Selangor, Malaysia.

Nordiana Mashros, School of Civil Engineering, Faculty of Engineering, Universiti Teknologi Malaysia, Skudai Johor, Malaysia.

Mohd Ezree Abdullah, Department of Civil and Environmental Engineering, Universiti Tun Hussein Onn Malaysia, Parit Raja, Batu Pahat, Johor, Malaysia.

Mohd Idrus Bin Mohd Masirin, Department of Civil and Environmental Engineering, Universiti Tun Hussein Onn Malaysia, Parit Raja, Batu Pahat, Johor, Malaysia. serious traffic problems such as road accident and fatality [3]. As seen, majority of the world's road traffic death occurred in developing countries compared to developed countries. World Health Organisation (WHO) recommended the import and adaptation of successful policies and effective countermeasures from developed countries in developing nations with the strategies and approaches to prevent this traffic problems from getting worse [4].

In Malaysia, the country is experiencing rapid growth of urban population with unprecedented road infrastructure expansion [5]. The population in Malaysia raised 1.1 percent from 2017 to 32.6 million population in 2018 [6]. Among the population, 84 percent are car owners [7], with the increasing number of private-vehicle owners and less people opt for public transport [8] result in increasing number of traffic on the road especially during business hours [9]. In additional to this, the geometrical design of the transport system which influences the drivers' behaviour contributing to the negative traffic impacts on the system [10], [11]. This result in Malaysia being among the highest traffic fatality rates in the world [12]. The long term strategies to lower the fatality rate is to develop urban planning with the interventions of transit-oriented development to encourage the use of public transportation and reduce the use of private transportation [13]. In additional to that, comprehensive policies are needed to address these problems of accommodation, land acquisition and traffic congestion [14]. Therefore, TIA is being adopted and applied in Malaysia.

Traffic impacts studies begins as part of the Environmental Impact Assessment (EIA) where traffic impacts in terms of noise, vibration and air pollution are being analysed in EIA [15]. As the effect of traffic impacts became more pronounce, traffic impact studies are taken into more serious consideration as an individual study of more detail and in-depth analysis [16]. This is when TIA is introduced but TIA do not have the same statutory status as EIA [17]. TIA is an assessment focuses on the traffic impacts generated by the development. The purpose is to assess the traffic impacts in a systematic and scientific study and to mitigate those impacts according to the appropriate measures [18].

Published By: 


\section{OBJECTIVES}

The objectives of this study are:

i. To identify the issues in the practice of TIA.

ii. To determine what constitute to the best practice from an international standard and where Malaysia stand in the standard

To propose a method to assess the performance of TIA practice in Malaysia.

\section{LITERATURE REVIEW}

\section{a. Issues in the Implementation of TIA}

TIA had been implemented in Malaysia since the early 90's [19] but traffic problems still continue to grow. Mainly because, the practice of TIA in Malaysia is not getting the attention or legal statutory as EIA to benefits from the advantages of TIA to its full potential in reducing the traffic impacts of the development. There are various issues faced in the implementation of TIA especially in developing countries and Malaysia do not shy from these issues [7], yet there are little studies conducted in addressing these issues. Political priority is the main reason for discrepancies between developed and developing countries [20]. TIA is well defined in developed countries with legal framework to promote the necessity of TIA and the stakeholders are dedicated to ensure TIA is implemented in an effective manner. Whereas, in developing countries, there are lacking in key elements in the practice of TIA, summarised in Fig. 1 .

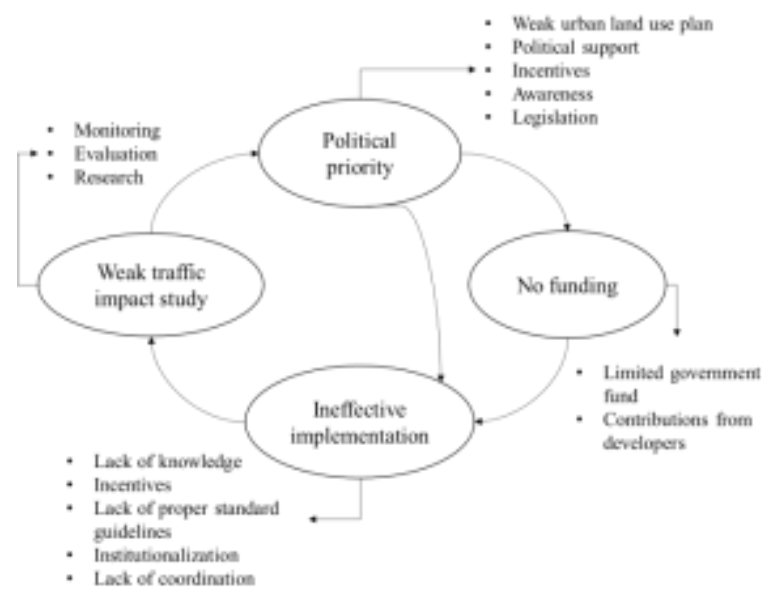

Fig. 1. Issues of the Practice of TIA in Developing Countries. Adopted from [20]

From the political priority, the practice of TIA is under weak urban land use plan and lacking of legal framework can be seen in the institutionalisation of TIA in major cities and lack of coordination between concerned parties that hinders the practice in the local regions. In additional, the experts or technicians do not have the sufficient knowledge and technical understanding on TIA in the government and consultants coupled with no incentives for improvement, the implementation of TIA still remain inefficient and unsuccessful [21]-[23]. This urge for the need of the concerning parties such academic person, community or civil society, government, developers and consultants to cooperate with each other to promote the necessity of TIA.

In terms of funding and budgeting, the government cannot possibly fund all the needed road improvements in time to meet the demands of new developments, particularly with the other demands for taxpayers funds [24]. Therefore, the government seeks contributions from the developer to assist in the implementation of road and traffic improvements required. However, there is no funding strategy available to assess the required contribution so there is a need for more rigorous and detailed analysis toward establishment of methods for funding the needed infrastructure [25], [26].

The current TIA framework is still lacking of review and monitoring requirements and little attention is given to the needs of other modes of traffic, such as walking, cycling and public transport [27], results in unstandardized TIA reports and at some areas, TIA is not being carry out [28]. Some guidelines do not have clarification in the responsibility of the parties in TIA and the establishment of this responsibility [29]. This requires the need for regulations that consider the whole province with established traffic engineering agency and last but not least more detail guidelines with more refined standard procedure. Overall, the issues in the practice of TIA is a cycle between political priority, no funding, ineffectiveness in the implementation and non-comprehensive TIA study.

\section{b. Purpose of TIA}

TIA is a technical appraisal of the traffic impact and safety implications relating to a development. It is the process of compiling, analysing information on, and documenting the effect that a development is likely to have on the operation of adjacent roads and transport networks [30]. It contains the standardised step-by-step procedure to determine traffic and transport related impacts. Also, to assist decision makers in reviewing the impacts and improves communication between the different stakeholders involved [18]. This assessment together with the support of environmental impact assessment, development planning and management, land-use policy and resource consent will provide the vital information and knowledge during making decision for the development applications [31].

The TIA report convey the findings in the assessment clearly and concisely to provide the decision makers the needed information. It provides information on the projected traffic expected from a proposed development and evaluates the impact of proposed development on the roadways in the immediate proximity of the proposed development. Moreover, it identifies potential traffic operational problems or concerns, recommend appropriate actions to reduce impact and promotes safety including vulnerable road users [32].

\section{c. $\quad$ Purpose of Guidelines}

Therefore, guidelines are necessary to standardise the conduct of the TIA study. It is important that the guidelines are sufficiently comprehensive so that the TIA are of suitable quality prior to granting of the development proposal approval. The guidelines will include the information regarding the legislative and policy frameworks

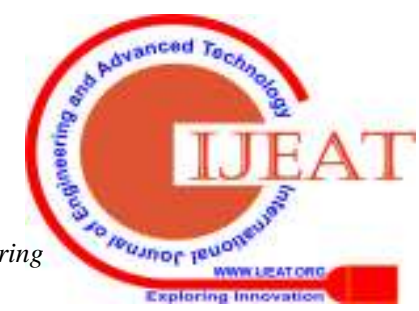


so that there will not be delays and revisions in the TIA process [27], [33].

The content of the guidelines should include the following:

i. Prescription of a preferred format for the practice of TIA.

ii. Outlines the statutory and policy framework of TIA.

iii. Description of the role and responsibility of the stakeholders.

iv. Prescriptions of the type of expertise and experience required by those preparing TIA.

v. Information for the stakeholders to understand the scope and requirement of TIA.

vi. Provision of the required detail to conduct and reflect the nature of the TIA study.

vii. Information on the duration of assessment validity.

viii. Provision of the minimum threshold values requiring TIA, flexible thresholds are preferred that relate to the scale and extent of the impact.

ix. Recommendation on a minimum study area.

x. Recommendation on the assessment year.

xi. Methodology used for traffic predictions.

xii. Technical guidance about baseline conditions and key assumptions.

xiii. List of potential impacts on the transport network.

xiv. Information about parking considerations, road link impacts and intersection impacts.

xv. Consideration of road safety and environmental impacts.

xvi. Complete with all the other issues that should be considered.

xvii. Method and list of item for mitigation.

xviii. Information of the travel plans, long-term management strategies that seek to deliver sustainable transport objectives.

The guidelines will promote uniformity, transparency and certainty among the stakeholders of the assessment and analysis, facilitate the early resolution of traffic and transport issues through the provision of timely and quality reports that reduce administration and rework and the need for discussion and negotiation between road authorities and developers.

\section{RESEARCH METHODOLOGY}

Table 1 shows the methodology and objectives of previous studies for the past 10 years. From the previous studies conducted in the topic of TIA, case studies had been the frequent used method to assess the practice of TIA in the respective countries. In Malaysia, there is limited studies on in this topic, only a few had case studies been done. The chronology of the studies are discussed below

\begin{tabular}{|c|c|c|}
\hline Refieraces & Methods & Objetives \\
\hline$[2]$ & $\begin{array}{l}\text { Case tady and } \\
\text { intervievs }\end{array}$ & Io undestend the prective of IIt in Australia \\
\hline [34] & Case sudy & 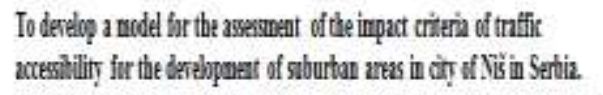 \\
\hline [35] & Cose sudy & 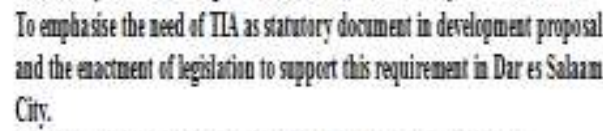 \\
\hline [36] & Case stady & 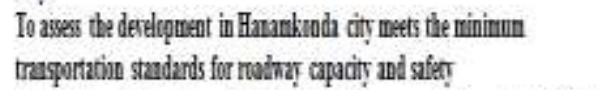 \\
\hline [2] & Cose thidy & 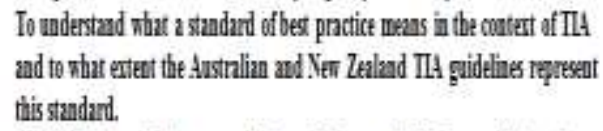 \\
\hline$[2]$ & Case sudy & 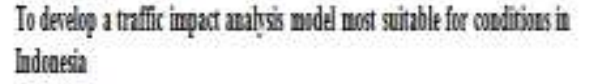 \\
\hline [37] & Cose sady & 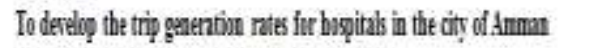 \\
\hline [39] & Case study & 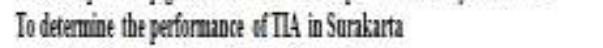 \\
\hline [2] & $\begin{array}{l}\text { Case study and } \\
\text { interviens }\end{array}$ & 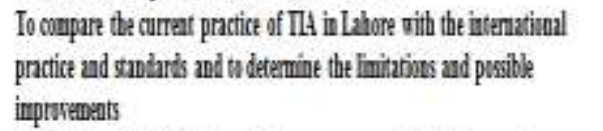 \\
\hline [3Y] & Case study & 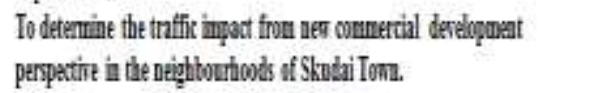 \\
\hline [H] & Cose this & To dertlop a uefhodobeg for TL in Dhaba ist \\
\hline [4] & Case endy & Io determine the peformance of TIA in Thailad \\
\hline$[4]$ & Case xady & Io disouss the future proppets of IIt in Jyea \\
\hline
\end{tabular}

In Malaysia, a study by [43] on the level of knowledge of the approving authority in the practice of TIA, Johor as case study concluded that the practice of TIA institutionalised in major cities, centralised with knowledgeable staffs but no so in local authority or municipal. This hinders the intention to have the local authority to act as the Approving Authority in TIA [44]. Minhans et al. (2013) study on the TIA of a proposed hypermarket in Skudai concluded that TIA is important in dealing with traffic impacts [39]. However, the issue found in the study is the rates given in the HPU Malaysian Manual is conservative and might not reflect the true conditions. The trips generated based on the manual are either underestimated or overestimated because the trip rated can be affected by a variety of socio-economic variables, this will have significant implication on the development of future traffic. In the study of the perceptions of professionals on TIA report in Malaysia [45], TIA report is an effective method in controlling traffic congestion problems. However there are different perspectives from the developers, they agreed to maintain TIA report as supportive report in the process of getting development order but they wish to save cost and for the application to proceed fast. This might result in TIA being viewed as merely a hurdle for development approval and will affect the integrity of the report and purposes. A study by [46] on the development of TIA criteria was dated 2001 which most of the issues are overcome with the gazette of the guidelines in 2011 but prior to that date, there are limited study conducted to understand the performance of the practice as it progresses. Till date, yet to have study conducted to assess the performance of TIA in Malaysia and how the guidelines in 
meeting the international standard.Case study is suitable because it is a research, through reports of past studies, allows the exploration and understanding of complex issues [47]. One of the reasons for the recognition of case study as a research method is about the limitations of quantitative methods in providing holistic and in-depth explanations of the social and behavioural problems in question. Through case study methods, a researcher is able to go beyond the behavioural conditions through the perspective of the people involved. By including both quantitative and qualitative data, case study helps explain both the process and outcome of a phenomenon through complete observation, reconstruction and analysis of the cases under investigation. The areas that have used case study methods extensively, particularly in government, management and in education. Case study allows the researchers to ascertain whether the practice of TIA were efficient or whether the goals of were reached. Case study relies on two additional sources of evidence, direct observation of event being studied and interviews of the persons involved in the events. The case study's unique strength is its ability to deal with a full variety of evidence, documents, artefacts, interviews and observations, beyond what might be available in a conventional historical study [48]. From this study, the problems in the process of TIA can be identified and suitable recommendations can be made to improve the efficiency of TIA in Malaysia. The findings of the research study will provide the necessary information for the practitioners in amending and modifying either in the legal framework, policies, guidelines, standard procedure of TIA.

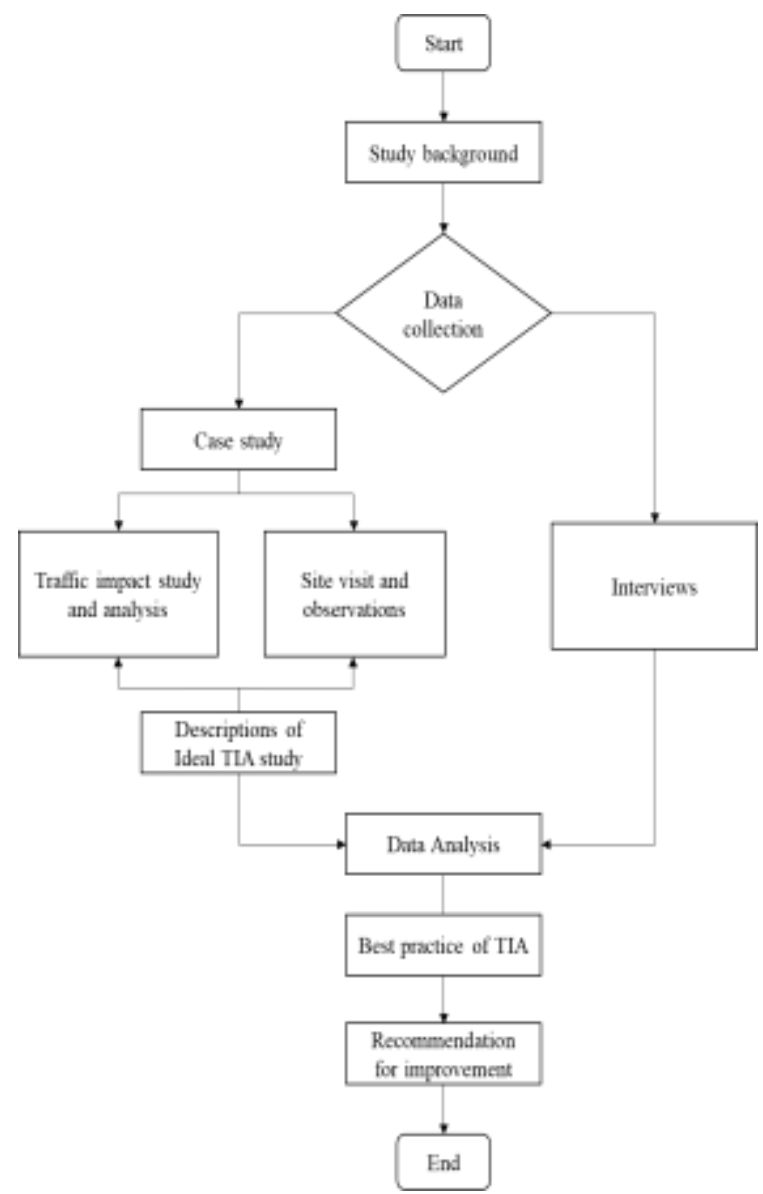

Fig. 2. Methodology of the study quantitative statistical results and understand the

Therefore, depending on the objectives of the study, case study is a suitable method to investigate the performance on TIA because there are vast data and variables to be collected to present the nature of TIA such as the study area, validity period, traffic study (traffic volume, speed during peak hour and trip generation), parking, traffic prediction, transportation plan and mitigation measures. Besides, to verify the data collected, secondary sources are needed such as interviews, survey and guidelines also contain hefty amount of data analysis and supporting details. Fig. 2 shows the flow of methodology to conduct the study.

\section{TIA IN DEVELOPED AND DEVELOPING COUNTRIES}

The comparison of the TIA guidelines across the countries will have similarities and differences, in return, illustrate how the system work in different contexts in hope to determine a constructive procedure with the optimal performance of TIA practice. However, due to the differences of environment situations, cultures, political systems and administrative capacities among the counties, this study interests in how these countries adopted the TIA system, the relation to standard TIA procedure and the scope of the analyses of the traffic impact. Understanding the requirements of best practice and the extent the available guidelines constitute this standard provide the knowledge for future revision and amendments of the TIA guidelines. Best practice by definition is always evolving. It is recognised as being the most appropriate way to assess or undertake some element versus some other way that may develop into best practice after peer review and development. [27] A study by Cooley, De Gruyter, and Delbosc (2016) concluded that the more recent guidelines do not mean the content is closer to the best practice. The length of the guidelines too doesn't constitute to the best practice.

The guidelines for traffic study in developed countries can be seen practicing as far back in the 1970s. The Institute of transportation engineers (ITE), 1991 [49] stated a compact analysis should at least have the seven critical items, deemed critical to the conduct. There are (1) the definition of the study area, (2) baselines study, (3) trip generation, (4) traffic management plan, (5) access points and routing analysis, (6) parking, and (7) the formulation of implementation mechanisms for recommended countermeasures. Most developed countries adopted this procedures and practice outlined by ITE and the guidelines that they had today outlines the details on the reviewing and monitoring process. Besides, they also shifting from a traditional traffic assessment approach, with private vehicle traffic impacts as the primary issue, towards transport assessment that consider accessibility and travel patterns for all transport modes [50]-[52].

While in developing country, the development of roads has brought extensive negative impacts for example, the deterioration of urban areas, increase in ineffective land use, increase in roads and traffic that affected the rates of deaths 
and accidents from vehicles [41]. The increase in the use of passenger vehicles and poor town planning [53] had led the authority to propose policies and guidelines for traffic analysis as well as enforcing laws and regulations in order to create standards in traffic impact analysis [54]. In developing countries, traffic impacts studies started off as part of the Environmental Impact Assessment (EIA) where traffic impacts in terms of noise, vibration and air pollution are being analysed in EIA [15]. However, as the effect of traffic impacts became more pronounce which can be seen in the happening of heavy traffic flow, traffic congestion and traffic accidents, traffic impact studies are taken into more serious consideration as an individual study of more detail and in-depth analysis [16]. In accommodating the countries development, TIA is being considered as a significant planning tool in land-use management and development proposal approval [55]. In the establishment of TIA, it still do not have the same statutory status as EIA [17]. Some countries such as Bangkok, Thailand [56] even without proper guidelines, due to the rapidly changing circumstances, TIA still being conducted but mainly in major cities. Among the TIA guidelines in the developing countries, the latest 2017 edition TIA guideline for developments in Singapore had the best summary on how the process of TIA study is carried out in a simple flowchart that shows the steps to guide the practitioners the right of way in the traffic study which is shown in Fig. 3 [57]. The guidelines consider the impacts other than vehicles such as public transport and walking and cycling plan which are not being emphasis by most of the developing countries that promote the element of sustainability in the traffic and transportation system. Besides, based on the flow in Fig. 3 the guidelines also consist the final phrase in post implementation review to ensure the efficiency of the implemented mitigation measures and the safety of the road users after the completion of the development

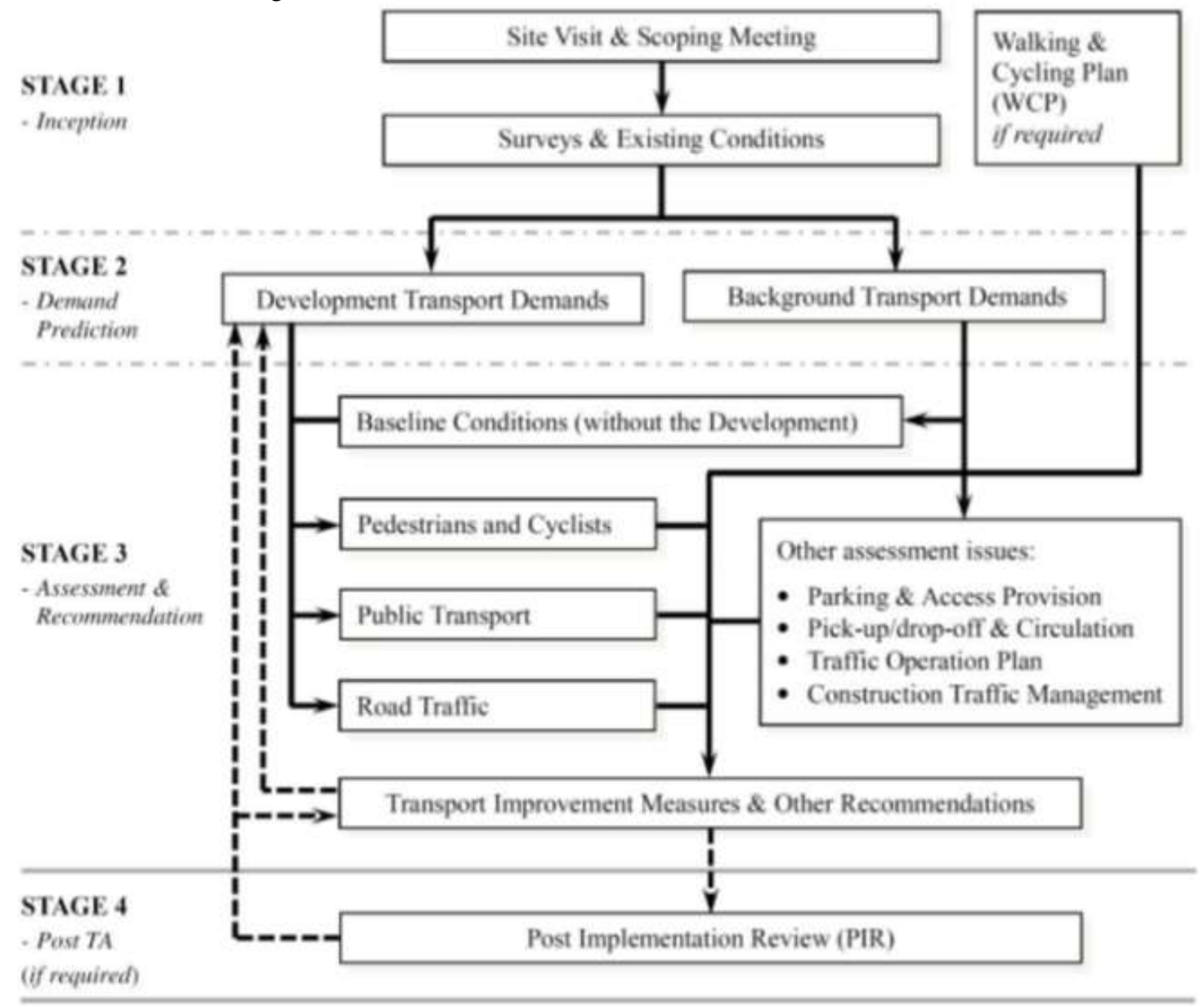

Fig. 3. Flow of traffic impact study. Source:[57]

\section{TIA FRAMEWORK IN MALAYSIA}

The guidelines are the backbone in the process of TIA, they are necessary to standardise the process of TIA study. The guidelines will include the information regarding the framework and legislations to promote uniformity among the stakeholders in facilitating the early resolution of traffic and transport issues through the provision of timely and quality reports [33]. In order to assess the performance of TIA in Malaysia, the understanding of the guidelines is vital to depict the implementation of TIA in the country.

Practitioners in Malaysia uses the Guidelines for Traffic Impact Assessment, REAM-GL 10/ [58] as a guide in the assessment of the development proposal. To enforce the implementation of TIA in the country, land use policy requires TIA report under section $21 \mathrm{~A}$ of the Town and

Published By: 
Country Planning Act 1976 (Act 172) [59]. The guidelines contain the information on the purpose TIA, the legislation, basic process, parties involved and their respective roles in TIA, accreditation of TIA assessor and the requirements in the TIA elements.

The three main parties defined in the guidelines are the approving authority, the developer and accredited TIA assessor. In the flow of planning permission application depicted in Fig. 4, the approving authority plays the major role as decision makers to verify the feasibility and rationality of a development proposal before proceeding with the application approval [1]. Approving authority in this context is the local authority and the road authority. It is vital that the approving authority has sufficient knowledge on the TIA to provide the necessary information to the developer and consultant to properly conduct the TIA study. In preparation for their roles, the practitioners should undergo training and formal education in traffic and transportation management [60]. Thus the guidelines also include the role of each parties and the accreditation of TIA assessor. However, the qualifications of the reviewers are not mentioned.

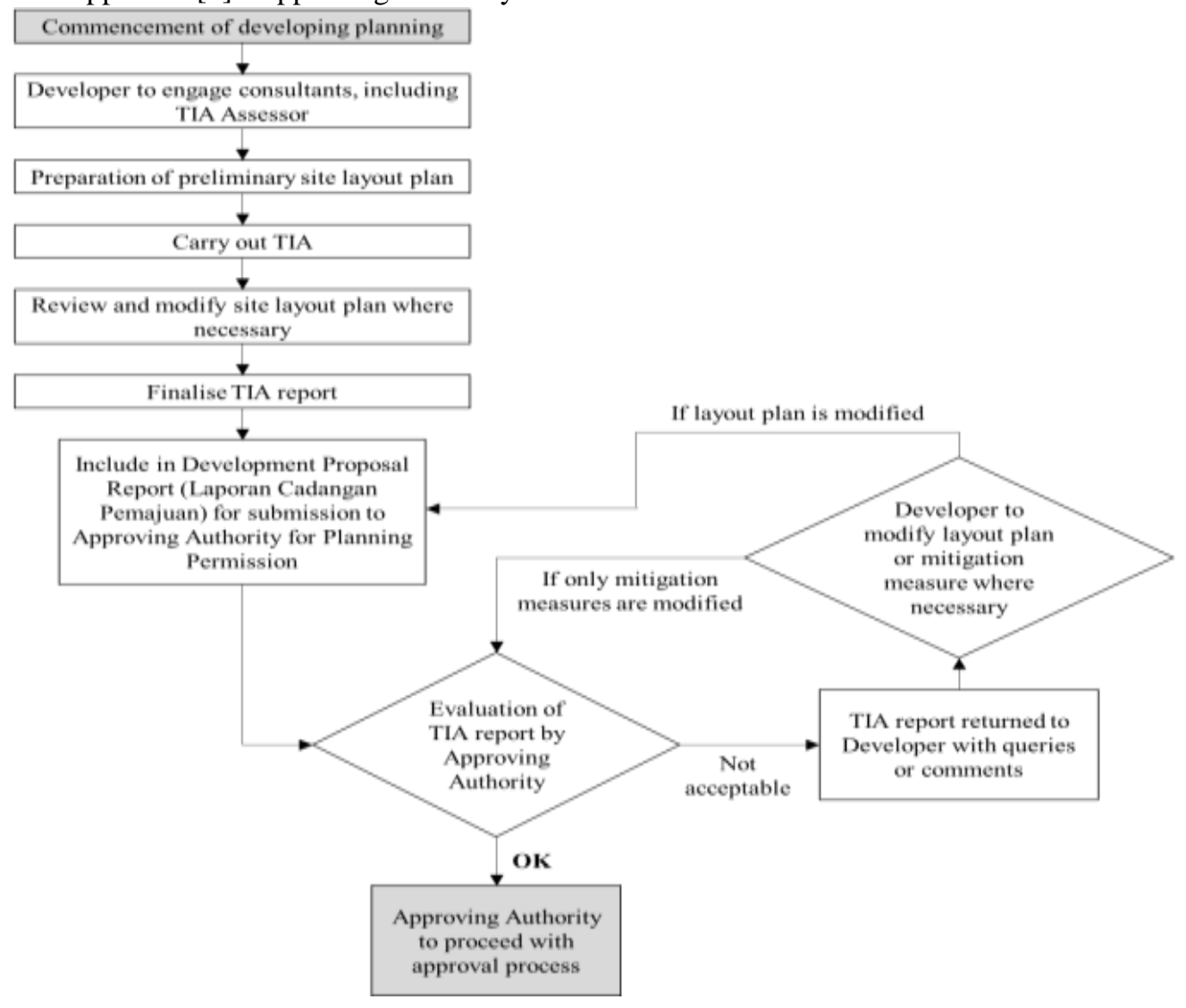

Fig. 4. TIA in planning permission application process. Source:[58]

The validity period of TIA is not more than 2 years from the date of a TIA study and its submission because the TIA must be up-to-date to reflect the latest traffic conditions of the locality. TIA is issued or warranted when the development meets the following criteria and trigger values as shown in Table 2. The computation of LOS is based on the recommendations of the latest version of the Highway Capacity Manual published by Transportation. Research Board of The National Academies of USA, with appropriate modifications given in the latest version of the Highway Capacity Manual Malaysia.
Table 2: Criteria and corresponding trigger levels to warrant TIA. Source: [58]

\begin{tabular}{lll}
\hline $\mathrm{N}$ & Criteria & Trigger Levels \\
\hline 1 & $\begin{array}{l}\text { Peak Hour Trip Generation } \\
\text { (Commuter peak) }\end{array}$ & $\begin{array}{l}150 \text { added vehicles per } \\
\text { hour (2-Way) }\end{array}$ \\
2 & $\begin{array}{l}\text { Off-Peak Hour Trip Generation } \\
\text { (Generator peak occurs at the } \\
\text { off-peak period) }\end{array}$ & $\begin{array}{l}200 \text { added vehicles per } \\
\text { hour (2-Way) }\end{array}$ \\
3 & Size of residential development & $\begin{array}{l}200 \text { dwelling units } \\
45.500 \text { sq.ft. (gross floor } \\
\text { area) }\end{array}$ \\
\hline
\end{tabular}

Note: Trip Generation Rates shall be based on the Malaysian Trip Generation Manual published by the Highway Planning Unit of the Ministry of Works, Malaysia

The items in the TIA report are listed as below:

1) Executive summary

2) Introduction (background and methodology)

3) Study are/boundary 
4) Existing traffic condition/ Baseline study (traffic volume, transportation system)

5) Land use study

6) Trip generation (trip attraction, trip distribution and trip assignment)

7) Impact Analysis (technique, result, locations)

8) Mitigation Measures (to meet the minimum level of service (LOS) of satisfactory road operation)

In the context of the international guidelines from developed and developing countries, the Malaysian TIA guidelines still lacking in details such as the review and monitoring process, information on funding and the emphasis on other mode of transport besides private vehicles. The main purpose of monitoring is to ensure that traffic impact mitigation measures has been adopted during project implementation [35]. The effective monitoring practices of road developments and strict enforcement of legislation will help to enforce the implementation of TIA [5]. The evaluators should track or monitor the implementation of mitigation measures of approved projects. At the same time, they must provide opportunities for the community to assess the changes. If developers do not follow the final agreement, there should be some punishment such as penalty charges. Having good quality data to monitor the impact of these efforts is critical to signifying their accomplishment. However, the monitoring is given much attention in the Malaysian TIA guidelines.

\section{CONCLUSION}

This study proposed case study as the suitable method to assess the performance of TIA in Malaysia since it is being implemented and practiced in the country. The identification of the issues in the practice of TIA in developed countries and developing counties by comparing the strength and weaknesses on the practice of TIA will show what constitute to the best practice from an international standard and how Malaysia in meeting those standards. The findings from the study will provide the practitioners the necessary information to make changes in the guidelines or policy to improve the effectiveness of TIA in Malaysia.

\section{ACKNOWLEDGMENT}

This study is supported by Research Management Center (RMC) research grant TIER 1 [vote number: H220] Universiti Tun Hussien Onn Malaysia

\section{REFERENCES}

1. J. Withanaarachchi, S. Setunge, and S. Bajwa, "Traffic Impact Assessment and Land Use Development and Decision Making," Int. Conf. Disaster Manag., pp. 256273, 2012.

2. S. Ardekani, E. Hauer, and B. Jamei, "Traffic Impact Models," in Chapter 7 of Traffic Flow Theory, Oak Bridge National Laboratory Report, 1992.

3. T. V. Mathew, "Congestion Studies," in Chapter 4 of Transportation Systems Engineering, 2014, pp. 1-17.

4. Y. Tanaboriboon and T. Satiennam, "Traffic Accidents in Thailand," in IATSS research, 2005, vol. 29, no. 1.

5. J. Campbell, "Road Risks \& Environmental Impact Assessments in Malaysian Road Infrastructure Projects,' pp. 13-16, 2018.
6. Department of Statistics malaysia, "Demographic Statistics Fourth Quarter 2018 Malaysia," 2019. [Online]. Available:

https://www.dosm.gov.my/v1/index.php?r=column/pdfPr ev\&id=UzliaFYxbW1nSFovbDYrLzFFR29zZz09.

7. K. Valley, "The 3 rd International Conference on Sustainable Future for Human Security The challenges of implementing urban transport policy in the," Procedia Environ. Sci., vol. 17, pp. 469-477, 2013.

8. R. Rahman, M. S. Nemmang, N. A. Nazimuddin, and H. A. Hamid, "Comparison of Traffic Speed Before , During and After 'Banci Lalu Lintas' at Federal Road ft005," MATEC Web Conf., vol. 103, p. 08004, 2017.

9. M. Rohani, U. Tun, H. Onn, B. D. Daniel, U. Tun, H. Onn, M. Y. Aman, U. Tun, H. Onn, J. Prasetijo, U. Tun, and $\mathrm{H}$. Onn, "Business hours vs non-business hours in business zone: Impact on speed and acceleration," $J$. Teknol., no. March, 2016.

10. M. S. Nemmang and R. Rahman, "An Overview of vehicles lane changing model development in approaching at u-turn facility road segment.," J. Teknol., vol. 78, pp. 59-66, 2016.

11. M. A. M. Bilema, M. M. Haurula, and R. Rahman, "The Study of Relationship Between Pedestrian and Safety based on the Theory of Planned Behaviour at Batu Pahat , Johor," MATEC Web Conf., vol. 103, p. 08010, 2017.

12. Nemmang M.S., Rahman. R, M. M. Rohani, and N. Mashros, "Analysis of speeding behaviour during approaching the U-turn facility road segment based on driving simulation test," in Matec Web of Conferences, 2017, vol. 103, p. 08008.

13. A. Abdelfatah, "Traffic Fatality Causes And Trends In Malaysia," Massachusetts Inst. Technol., pp. 1-19, 2016.

14. U. Yaakob, T. Masron, and F. Masami, "Ninety Years of Urbanization in Malaysia: A Geographical Investigation of Its Trends and Characteristics," pp. 79-101, 2010.

15. Y. Muromachi, I. Lim, A. Wicaksono, K. N. Vergel, K. Choocharukul, V. Hong TAN, K. Terai, D. Fukuda, and T. Yai, "A Comparative Study on Road-based Urban Public Transport Policies in Six Asian Countries from the Viewpoint of Governance, Urban Planning, and Financial Aspects," J. East. Asia Soc. Transp. Stud., vol. 11, pp. 1433-1450, 2015.

16. Myanmar Japan Thilawa Development LTD., Environmental Impact Assessment for Industrial Area of Zone B. 2016.

17. I. M. Schoeman, "Application of traffic impact studies as part of the EIA process: a case study as applied to the extension of a mineral processing plant," vol. 130, pp. 519-531, 2013.

18. M. I. Faheem, "A Frame Work for Traffic Impact Analysis," Interational J. Eng. Econ. Manag., vol. 1, no. 1, pp. 5-9, 2012.

19. A. Zulkiple, R. Atiq, and A. O. K. Rahmat, "Interactive Traffic Impact Assessment Study,” 2008.

20. K. Jadaan, E. Al-braizat, S. Al-rafayah, H. Gammoh, and Y. Abukahlil, "Traffic Safety in Developed and Developing Countries : A Comparative Analysis," vol. 6, no. 1, pp. 1-5, 2018.

21. N. Azra and S. Hoque, "Implementation of Traffic Impact Assessment in Developing Countries : Case Study of Bangladesh," Proc. Intl. Conf. Futur. Trends Civ. Struct. Eng., 2014.

22. K. Limapornwanitch, C. M. Montalbo, K. Hokao, and A. Fukuda, "The Implementation of Traffic Impact Assessment in Southeast Asian Cities: Case Studies of Thailand and The Philippines," J. East. Asia Soc. Transp. 
Stud., vol. 6, pp. 4208-4223, 2005.

23. H. S. Lidasan, I. C. Espada, and M. R. C. De Leon, “A Needs Assessment of Transport Planning and Traffic Management of Local Cities: The Case of the Philippines," J. East. Asia Soc. Transp. Stud., vol. 8, pp. $16-27,2010$.

24. E. A. Smith and K. Tara, "Who should pay for the transportation infrastructure needed for new developments?," in Proceedings 15th ARRB Conference, 1990, pp. 17-31.

25. G. Shiran, J. Black, and K. Tara, "Traffic Impact Assessment of Land Use Proposals: Fifty Years of Australian Experience," Int. J. Transp. Eng., vol. 6, no. 4, pp. 381-393, 2019.

26. K. D. Yayat, B. Kombaitan, Pradono, and H. P. H. Purboyo, "Traffic Impact Assesment Practice in Indonesia," Procedia - Soc. Behav. Sci., vol. 227, pp. 75 80, 2016.

27. K. Cooley, C. De Gruyter, and A. Delbosc, "A best practice evaluation of traffic impact assessment guidelines in Australia and New Zealand," Australas. Transp. Res. Forum, no. November, pp. 1-21, 2016.

28. Z. Abbas, G. A. Anjum, and L. D. Authority, "Traffic impact assessment practice in pakistan: case study of lahore," 2014

29. J. F. Van Rensburg and S. C. Van As, "Issues with Traffic Impact Assessments," Proc. 23rd South. African Transp. Conf., vol. 12, pp. 654-661, 2004.

30. K. S. Weerasekera, "Impact on Existing Transport Systems by Generated Traffic due to New Developments," vol. XXXXIV, no. 03, pp. 31-37, 2011.

31. S. Atchia, "Traffic Impact Assessment Toolkit for Africa cities.," 2017.

32. K. Hokao and S. S. Mohamed, "Traffic impact mitigation for new developments: A way to reduce traffic congestion in major cities.," Transp. Commun. Bull. Asia Pacific 68, pp. 1-32, 1999.

33. I. Clark and M. Faid, "Guidelines for undertaking Transport Assessments in New Zealand and Australia," Aust. Inst. Traffic Plan. Manag. Natl. Conf., 2007.

34. M. Stankovi, "Selection Criteria and Assessment of the Impact of Traffic Accessibility on the Development of Suburbs," 2018.

35. G. Kazaura Wilfred and M. Burra Marco, "Land Use Change and Traffic Impact Analysis in Planned Urban Areas in Tanzania: The Case of Dar es Salaam City," Curr. Urban Stud., vol. 5, no. 1, pp. 1-19, 2017.

36. B. K. Naik and P. Gopi, "Traffic impact assessment for hanamkonda city," vol. 7, no. 8, pp. 160-168, 2017.

37. M. Naser, S. A. Qdais, and H. Faris, "Developing trip generation rates for hospitals in amman," Jordan J. Civ. Eng., vol. 9, no. 1, pp. 8-19, 2015.

38. S. Larastiti and B. Yulianto, "Kinerja Analisis Dampak Lalu Lintas," 2015.

39. A. Minhans, N. H. Zaki, and R. Belwal, "Traffic impact assessment: A case of proposed hypermarket in Skudai town of Malaysia," J. Teknol. (Sciences Eng., vol. 65, no. 3, pp. 1-7, 2013.

40. N. Sharmeen, "Developing a Generic Methodology for Traffic Impact Assessment of a Mixed Land Use in Dhaka City," vol. 5, no. December, 2012.

41. N. Pomlaktong, R. Jongwilaiwan, P. Theerawattanakul, and R. Pholpanich, "Chapter 12: Road Transport in Thailand," in The Impacts and Benefits of Structural Reforms in the Transport, Energy and Telecommunications Sectors in APEC Economies: AsiaPacific Economic Cooperation, 2011, pp. 267-289.

42. T. Seki and M. Akirarin, "Organize and future outlook of the traffic assessment in large-scale development," vol. 66, no. 2, pp. 255-268, 2010.
43. L. Wei May, R. Rahman, M. F. Hassan, and M. Rohani, "The Study on the Level of Knowledge of the Approving Authority in the Practice of Traffic Impact Assessment (TIA) Report Submission in Malaysia: A Case Study in Johor," in 10th Malaysian Road Conference, 2018.

44. L. Wei May, R. Abd Rahman, M. F. Hassan, N. Mashros, J. Md Diah, and M. I. Mohd Masirin, "Knowledge Assessment of the Practice of Traffic Impact Assessment among the Authority in Johor, Malaysia," Presented in 6th Int. Conf. Business, Sci. Technol. (ICBST 2019). to be published.

45. S. J. Chuah, "The perceptions of professionals on the traffic impact assessment (TIA) report," Universiti Teknologi Malaysia, 2010.

46. W. Ka Siong, "Development of traffic impact assessment ( TIA ) criteria in Malaysia; Johor state as the basic model," 2001.

47. R. K. Yin, "Case Study Design and Methods," Appl. Soc. Res. Methods Ser., vol. 5, 2003.

48. R. K. Yin, Application of Case Study Research, 3rd ed SAGE Publication, 2012.

49. Brian S. Bochner, Traffic Access and Impact Studies for Site Development. Washington D.C.: Institute of Transportation Engineers, 1991.

50. F. Fisal, N. Sabahiah, A. Sukor, and H. Halim, "Comparison of traffic impact assessment (TIA) and transportation assessment (TA).," in AIP Conference Proceedings, vol. 2030, no. 1, p. 020275, 2018.Department for Regional Development and Department of the Environment, Guidelines for Development Proposals in Northern Ireland, no. November. UK, 2006.

51. T. Shane and F. Melissa, "Transport impact guidelines for site development August 2007," in IPENZ Transportation Group Conference New Plymouth, 2008, no. August.

52. C. K. Leong, "The Impact of Traffic Congestions on Tourist Behavior : Case study of Chiang Mai , Thailand," in 14th ApacChrie Conference 2016, Bangkok, Thailand, 2015, pp. 290-300.

53. Ministry of Transport Thailand, "A Meeting to Consider The Report of the Review and Progress of Traffic Impact Assessment," 2018. [Online]. Available: http://www.otp.go.th/index.php/search/view?key=TRAF FIC+Impact+Assessment.

54. J. Stærdahl, H. Schroll, and N. Dewar, "Environmental Impact Assessment in Malaysia, South Africa, Thailand , and Denmark: Background, layout, context, public participation and environmental scope .," vol. 3 , no. 1, 2004.

55. J. Peraphan and J. Sittha, "Planning our way ahead: A review of Thailand's transport master plan for urban areas," Transp. Res. Procedia, vol. 25, pp. 3989-4006, 2017.

56. Land Transport Authority, Transport Impact Assessment Guidelines for Developments. 2017.

57. Road Engineering Association of Malaysia, Guidelines for Traffic Impact Assessment. Road Engineering Association of Malaysia, 2011.

58. The Commissioner of Law Revision Malaysia, Act 172 Town and Country Planning Act 1976. The Commissioner of Law Revision Malaysia, 2006.

59. M. Kutz, Handbook of Transportation Engineering, Second. McGraw Hill, 2011. 